\title{
Viktor Mayer-Schönberger, Delete: the virtue of forgetting in the digital age
}

\author{
Matthew L. Smith
}

Received: 4 January 2010 / Accepted: 18 January 2010 / Published online: 17 February 2010

(C) The Author(s) 2010. This article is published with open access at Springerlink.com

Much ink has been spilt theorising and documenting the transformation of our societies from an industrial age towards an information age (Webster 2002), network society (Castells 2001), or knowledge society (Mansell and Wehn 1998). Central to these visions is the importance and relatively free flow of massive amounts of information based upon new information and communication technologies. Indeed, a large part of the world is experiencing an information explosion with significant institutional and social implications (Kallinikos 2006).

This surfeit of information is generally viewed as a net social positive. Opening access to a wide range of data is viewed as an essential input for social gains across different social domains such as education, health, and even governance, especially in developing countries (Benkler 2006; Smith and Elder forthcoming). If information is power, the open access to it can be a democratizing force. Read-write web (web 2.0) technologies have taken openness to a new level, lowering transaction costs for collaborative production of information and other goods in novel ways (Benkler 2002; Lessig 2006; Shirky 2008). Of course the story is more complex than this as any social transformation brings threats as well as benefits: issues of information privacy, surveillance societies, intellectual property rights, inter alia, all need to be taken seriously as potentially negative social consequences.

Delete: The Virtue of Forgetting in the Digital Age, an engaging, and wellresearched book by Mayer-Schönberger, wades into this debate, painting a potentially dystopian future where an individual's digital past may constrain their present. Delete ponders how individuals and societies will be altered as we move toward a world where all of our digital transactions leave permanent digital traces. While Delete focuses on the potentially negative social consequences, it is by no means a pessimistic account; rather Mayer-Schönberger constructively engages with the existing gamut of proposed fixes and offers his own admittedly partial and

M. L. Smith ( $\square)$

International Development Research Centre, Ottawa, Canada

e-mail: msmith@idrc.ca 
limited solution that directly challenges the primacy of information: the reintroduction of forgetting.

Delete begins by piquing our interest and concern with two anecdotes of present-day lives that have been constrained in unanticipated and, to most, unjust ways as a direct consequence of the digital traces they have left behind: a young lady whose teaching certificate is denied when a My Space photo with the title 'Drunken Pirate' was passed on to school officials (she has since sued the college and lost), and a psychotherapist who is permanently restricted from entering the US because a US border guard Googled a paper he wrote over 30 years ago where he admitted to taking LSD. For Mayer-Schönberger these are two of the proverbial warning shots over the bow indicating the larger societal risks if there is no movement to right the current imbalance of power over who controls personal information.

In chapters 2 and 3, the author jumps right into the heart of his argument by pinpointing what might be a key inflection point in our current societal transition: in a digital world, remembering information has become the default mode of human behaviour. This is perhaps the most interesting assertion and greatest contribution of the book; indeed, this section alone makes it worthy of the adulation it receives on its back cover. Mayer-Schönberger persuasively illustrates how, since the dawn of time, the default mode of information management by humans and societies has necessarily been to forget - as remembering comes with high inherent costs. Delete traces the history of remembering and forgetting, the role of language, and external storage devices (such as oral stories and the printing press and paper) and shows how they have had a profound role on the very nature of society. However, the price of storage has so drastically plummeted it is now more cost-effective to keep data in storage than to spend time deleting them. While at first blush this may seem innocuous enough, and even beneficial, for Mayer-Schönberger it is the basis for negative implications both small and large. These concerns are based on at least two fundamental observations. First, in the current form of our digital age "our capacity as individuals to control information is vastly reduced" (p. 90). Second, and more speculatively, it constitutes a radical transition overturning thousands of years of social evolution with unknown and potentially negative ramifications.

Having laid the first premise of the argument, chapter 4 sketches out "the contours of the challenges we face" (p. 97). There are two separate but interrelated challenges that are summarized by two words: power and time. The challenge of power is a question of who controls what information in our digital world. The central argument here is that individuals, for a variety of reasons, are losing power relative to their personal information as it shifts to known and unknown others. In a world where governments and corporations can gather, store, and mine individuals' digital traces, this shift in control over information further entrenches existing power asymmetries. Furthermore, the relative durability of the information means that this shift in power happens through time. In particular, Mayer-Schönberger argues that these digital traces can act much like a digital surveillance panopticon with subsequently chilling effects on human behaviour. In a nutshell, the author is describing the potentially anti-democratic tendencies and threats to information privacy that occur with an expansion of information flows in a political economy 
without the adequate mechanisms in place (legal, technical, or cultural) to balance power asymmetries. While this challenge is not novel, with its roots in the information society, information privacy and surveillance society literatures, Mayer-Schönberger's original premise concerning the inability to forget makes these challenges even more concerning and relevant than they were just a decade ago.

The second challenge of time is more novel and focuses on potentially detrimental constraints on our ability to act wisely when we have so much digital memory,

“... comprehensive digital remembering collapses history, impairing our judgement and our capacity to act in time. It denies us humans the chance to evolve, develop, and learn, leaving us helplessly oscillating between two equally troubling options: a permanent past and an ignorant present" (p. 127).

This is a decidedly weaker and more speculative argument than the challenge of power. However, Mayer-Schönberger is correct, it is troubling.

While it is clear that the current context of digital memory is a novel social development, and presents a new set of challenges, it remains to be seen if it is a greater social impairment than our more forgetful past. Is a more complete historic record of events necessarily worse than a history that is ultimately written by the victors, as the saying goes? While digital information may be necessarily incomplete, wasn't decision-making similarly constrained by incomplete and acontextual information in the past? Furthermore, adjustments will be and are already being made to cope with or even thrive within this new environment. Indeed, for some there is no such thing as "too much" information, as new techniques are constantly being devised to manage and mine this "glut" to improve decision-making and other human activities (Weinberger 2007).

What does seem more plausible is the reduced ability for individuals and society to forgive if we never forget - ultimately limiting our abilities to change and define ourselves in the present and future. Imagine someone who is charged with a crime that is recorded by a local newspaper. This digital trace will be at once both global and durable, even if the individual is ultimately acquitted of the crime. While the acquittal may also leave a digital trace, in certain cases, especially for highly culturally sensitive crimes and in less accepting social environments, a lingering suspicion will haunt the individual for the rest of their life. Mayer-Schönberger admits that an inability to forgive is not a foregone conclusion as societies may adapt by ultimately adjusting their tolerance levels for human foibles especially in a world where it is impossible to forget mistakes. At a minimum, however, there will be a painful adjustment period in the interim.

The following two chapters, 5 and 6 , move back from speculation to the very concrete and constructive engagement with the set of existing solutions to the challenges Mayer-Schönberger has brought to light. He explores a range of technical, legal, and social approaches to address both the power and time dimensions. Delete then explores the potential of reintroducing forgetting as one mechanism that, if implemented appropriately for the given context and in conjunction with other mechanisms, might aid with the decision-making challenges - and even help to shift control over information back to the individual. 
While the efficacy and feasibility of Mayer-Schönberger's solution is something that is debatable, such a nuanced and critical engagement of ideas is clearly what is needed at this point in time, and is welcome reading.

Particularly interesting would be more research and thinking about exactly what types of information might impair or constrain future actions and decisions, and in what situations. As Mayer-Schönberger suggests, the answer will depend both upon the type of information and the context (p. 194). However, one can imagine sketching out the contours of these details to help improve our information management choices today. Certainly, one place where the ability to forget appears paramount is the ability for individuals to have control over their own pasts to facilitate social forgiveness and help individuals determine their own present. However, opening and storing what types of government information? Indeed, it is still an open question as to what types of information might bring about the sort of changes we are looking for in government (Lessig 2009). On balance, however, if a central concern is one of power-asymmetries and the control of information, it would seem that we would much rather shine the light of transparency on governments rather than citizens (Castells 2001, p. 185).

Overall, Delete is a book about information and its relationship to power, forgiveness, forgetting, and freedom: the power to maintain some control over the digitally recorded past to ensure freedom in the present. While at points Delete engages in (necessarily) speculative and sometimes not entirely convincing argumentation laced with an overly romanticized view of the past, it is a poignant and extremely timely warning for us to take a step back and think about how we construct our future in an age where information is king. Delete doesn't seek to provide a definitive solution, but rather, it succeeds in the more modest but equally important goal of contributing to a "wide-ranging, open, and intense discussion about forgetting, and how we can ensure that we'll remember its importance in our digital future" (p. 199).

Interestingly, it appears that Mayer-Schönberger's contribution can already be felt. During the course of writing of this review, a "right-to-forget" law was proposed in France that would give Internet users the option to delete information that is stored about them (Reid 2010). Clearly the conversation has begun, and Delete is well placed to contribute.

Open Access This article is distributed under the terms of the Creative Commons Attribution Noncommercial License which permits any noncommercial use, distribution, and reproduction in any medium, provided the original author(s) and source are credited.

\section{References}

Benkler Y. Coase's Penguin, or, Linux and the nature of the firm. The Yale Law Journal. 2002;112:369446.

Benkler Y. The wealth of networks: how social production transforms markets and freedom. New Haven: Yale University; 2006.

Castells, M. The internet galaxy: Oxford University Press; 2001.

Kallinikos J. The consequences of information: institutional implications of technological change. Cheltenham: Edward Elgar; 2006. 
Lessig L. Free culture: the nature and future of creativity. New York: Penguin; 2006.

Lessig, L. Against transparency: the perils of openness in government. The New Republic; 2009.

Mansell R, Wehn U (Eds.). Knowledge societies: information technology for sustainable development. Oxford University Press; 1998.

Reid D. France ponders right to forget law. BBC News. 2010. URL http://news.bbc.co.uk/2/hi/ programmes/click_online/8447742.stm

Shirky C. Here comes everybody: the power of organizing without organizations. New York: Penguin; 2008.

Smith ML, Elder L. Open ICT ecosystems transforming the developing world. Information Technologies and international development; forthcoming.

Webster F. Theories of the information society. 2nd ed. London: Routledge; 2002.

Weinberger D. Everything is miscellaneous: the power of the new digital disorder. New York: Henry Holt and Company, LLC; 2007. 